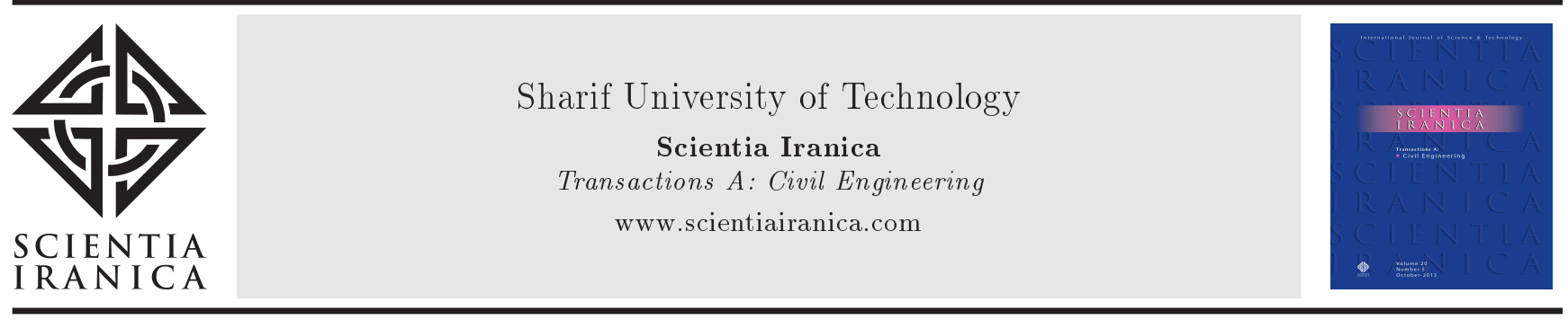

\title{
Multi-criteria optimization of concrete arch dams
}

\author{
M. Pouraminian ${ }^{\mathrm{a}}$ and M. Ghaemian ${ }^{\mathrm{b}, *}$ \\ a. Department of Civil Engineering, Science and Research Branch, Islamic Azad University, Tehran, Iran. \\ b. Department of Civil Engineering, Sharif University of Technology, Tehran, Iran. \\ Received 20 October 2015; received in revised form 1 March 2016; accepted 5 June 2016
}

\author{
KEYWORDS \\ Multi-objective \\ particle swarm \\ optimization; \\ Conic function; \\ Pareto front; \\ Concrete arch dam; \\ Safety criteria; \\ Economic criteria; \\ Decision-making.
}

\begin{abstract}
In this study, multi-criteria shape optimization of an asymmetrical doublecurvature arch dam is presented. Simultaneous cost minimization of dam construction and maximum allowable tensile stress are investigated for an economical and safe design approach in the current study. Pareto front method was used to balance both the economy and safety of the design simultaneously, which can be difficult for both analysts and decision-makers. A non-dominated solution based on the important parameters of dam analysis and design is presented. To help decision-makers in their decision, two different methods are proposed. These methods for the case of an arch dam are Lombardi coefficient and equilibrium point methods. The obtained results indicate that these two methods can be helpful for designers without experience and information of previous designs.
\end{abstract}

(C) 2017 Sharif University of Technology. All rights reserved.

\section{Introduction}

Dams are an important part of infrastructures to a nation. Dam safety is the main concern of governments due to the potential of destruction in case of failure and subsequent damages to the life, property, and environment of the downstream population. Dam safety in design consists of safe withstanding of applied loads and construction economy. Shape optimization is a tool to minimize construction cost of arch dams. The costs of dam construction consist of volume of concrete, formwork, and foundation excavation. In recent years, numerous studies have been done on the optimization of arch dams to reduce the volume of concrete in arch dam construction. In the conducted research, the goal is to minimize the volume of used concrete in the dam body in order to reduce the cost of dam construction [118]. Stress and geometric constraints are included as prerequisites for an optimal design in optimization process. Takalloozadeh et al. in 2014 conducted a study about the optimal shape of arch dams considering

*. Corresponding author. Tel.: +982166164242

E-mail address: ghaemian@sharif.edu (M. Ghaemian) abutment stability [1]. Pourbakhshian et al. in 2015 utilized sensitivity analysis in the shape optimization of concrete arch dams [3]. Seyedpoor et al. in 2009 conducted a study about shape optimization of concrete arch dams subject to earthquake loading [9]. They used a meta-heuristic particle swarm optimization algorithm for optimization. Sun and Du took strain energy into account as an objective function which has managed to reduce the strain energy and deformation modules for optimized design [19].

Multi-criteria optimization of arch dam has been studied and the volume of concrete is considered as the first objective function with principal tensile stress of dam body as another objective function [19-25]. Importance of tensile strength in unreinforced concrete arch dams makes it as an important parameter to affect the dam design. In an optimization process, optimization of arch dam and other structures could transform a multi-objective problem into a singleobjective optimization problem which is called classical multi-objective optimization method or decomposition method. In this method, an optimization problem with m-objective can be rewritten as an M-factor term, in which the coefficients of each of the objectives show 
the importance of that objective function for decisionmakers, and sum of coefficients should be equal to one [19-26].

Multi-objective optimization of concrete arch dams has been the subject of many studies for the last decade [19-25]. Wen-jun et al. used the fuzzy theory to deduce both dam volume and maximum tensile stress as objective functions [20]. The results indicated effectiveness of the method. Sun Linsong et al. established a multi-objective optimization process for the optimum shape of concrete arch dams consisting of four objectives of dam volume, maximum tensile principal stress, maximum compressive principal stress, and relative depth of high tensile stress zone at the dam base [21]. The results showed that game theory method is better than utopia point method in the field of multi-objective optimization of arch dams. Hai et al. conducted some investigation on minimizing both dam volume and maximum tensile stress in shape optimization of high arch dam based on linear programming model, and results indicated that the Bin-objective results can be a reference to the designer [22]. In another work by Neng-gang et al., an unselfish cooperation game was used in multiobjective shape optimization of arch dam with threeobjective functions including concrete volume of dam body, maximum tensile principal stress, and dam body strain energy [23]. The optimization process resulted in a decrease of all three-objective functions. Neng-gang et al. utilized mixed behavior game player model for multi-objective shape optimization of arch dam with tri-objective functions taken as the concrete volume of dam body, maximum tensile principal stress, and dam body strain energy [24]. The proposed method was found to be effective in arch dam optimization problems. Lin Song et al. introduced a robust shape optimization method for arch dams by taking strain energy of dam body and sensitivity to the deformation modulus of foundation as objective functions [19]. Results found that the proposed method could effectively reduce the sensitivity of dam strain energy to foundation deformation modulus. It is remarkable that most of the previous research papers on multiobjective shape optimization of concrete arch dams used decomposition method in order to solve vector optimization problems.

In this research, meta-heuristic optimization algorithms are used to solve the optimization problem of arch dam. Optimization problems are solved by simultaneously seeking the design variables' space to improve objective functions. These methods are also called intelligent optimization methods or evolutionary. The optimization techniques based on the trade-off front are used which resulted in many answers. Pareto methods are implemented to find a set of efficient optimum solutions. Choosing the best solution among the set of optimum solutions is difficult. Analysis of post-Pareto front based on some important parameters in the optimization of arch dam is carried out to choose the best solution.

\section{Statement of the optimization problem}

Shape optimization of arch dams is one of the challenging problems in optimization. In the process of optimization, both of objective function and constraint conditions are considered to be nonlinear. In this study, optimization process is carried out for an asymmetric dam. Mathematical expression of optimization problem in a standard form can be expressed as follows:

Find $X=\left(x_{1}, x_{2}, x_{3}, \ldots, x_{n}\right\}^{T}$,

Minimize : $F_{X \in \mathcal{F}}=\left\{f_{1}(X), f_{2}(X)\right\}$,

Subject to :

$$
\begin{aligned}
& g_{i}^{U N S}(X) \leq 0 ; g_{i}^{U S}(X) \leq 0, \\
& i=1,2, \ldots, m, \\
& a_{L} \leq X \leq b_{U},
\end{aligned}
$$

where $X$ is the vector of design variables; and $f$ is feasible space; $a_{L}$ and $b_{U}$ are lower and upper limits; and $g_{i}(X)$ is inequality constraints for the first and second load combinations.

\subsection{Objective functions}

Two objective functions are considered according to the following:

$$
\begin{aligned}
& f_{1}(X)=\sum_{j=1}^{A} V_{j} \\
& f_{2}(X)=\max \left(S_{1 \max }^{1}, S_{1 \max }^{2}, \ldots, S_{1 \max }^{A}\right),
\end{aligned}
$$

$V_{j}$ is the $j$ th element's volume and $A$ is the total number of elements of dam body. Also, $S_{1 \max }$ is maximum principal tensile stress of elements of dam body.

\subsection{Design variables}

In this study, 33 design variables are taken into account as the design variables vector for arch dam optimization problem. Horizontal arches are defined to be parabolic functions at four different elevations. Design variables of horizontal arches at different elevations are shown in Figure 1. It is shown that 4 radiuses and 3 thicknesses are assigned to each horizontal arch. Two radiuses out of four aforementioned radiuses are related to upstream face and two are related to downstream face. In an asymmetric arch dam, arches contain separate left and right radiuses. The vertical arches of crown 


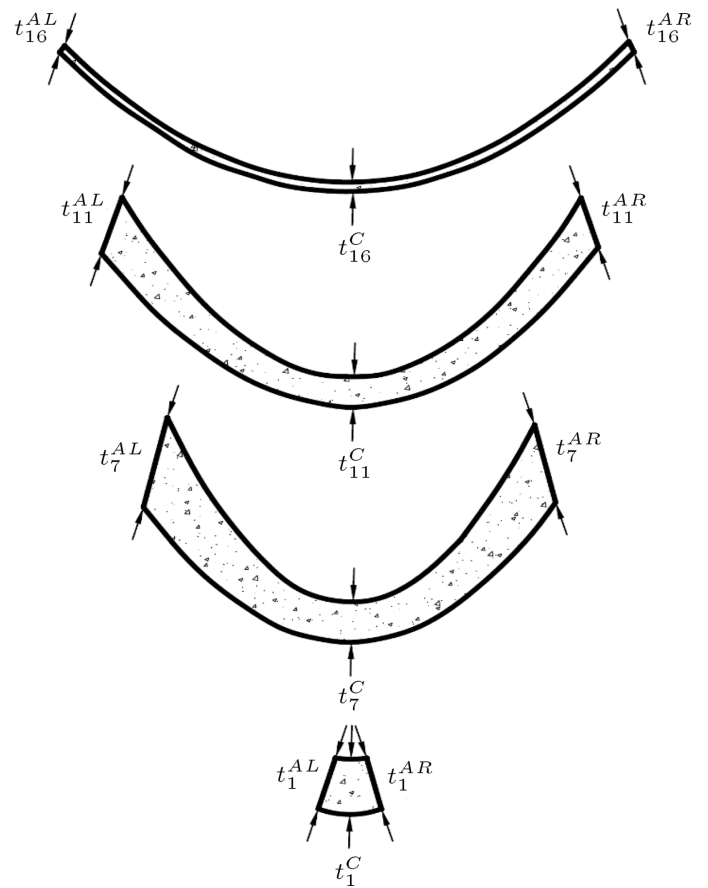

Figure 1. Design variables of horizontal arches at specific elevations.

cantilever curve are defined by five variables which will be discussed in the next chapter. A list of design variables used in the optimization problem is shown in Table 1.

\subsection{Constraints}

Most of the constraints used in engineering optimization problems are the inequality constraints. Three types of constraints, namely stress, geometric, and stability, are considered. The maximum existing stress in the dam body under imposed loads should be limited to the allowable stress of materials. Allowable tensile stress of materials is obtained from the formula proposed by Raphael in the following [27]:

$$
f_{t}^{\prime}=0.324 f_{c}^{\prime 2 / 3}
$$

where $f_{c}^{\prime}$ is uniaxial compressive strength of concrete. For dam concrete of $25 \mathrm{MPa}$, allowable tensile strength would be $2.77 \mathrm{MPa}$.
In the present study, two load combinations are considered as given in Eq. (4):

$\mathrm{UNS}=$ Stage construction,

US $=$ Hydrostatic loading + stage construction.

UNS is an unusual static load combination due to selfweight which considers effects of dead load stage construction. The compressive stress safety factor is 2.5 , while tensile stress safety factor is taken to be 1 [28]. Therefore, allowable compressive stress for this load combination would be $10 \mathrm{MPa}$. US load combination is due to UNS and hydrostatic reservoir pressure at normal water level. The recommended safety factor is 4 for compressive stresses and 1 for tensile stresses. The allowable tensile stress for concrete would be $6.25 \mathrm{MPa}$. Applied geometric constraints consist of the fact that the thickness of left and right abutments of horizontal arch is greater than the thickness at the center of arch and also thickness of the crown cantilever from the base to the crest continuously reduces. To provide sufficient ease in the construction process, maximum slope of overhang at the upstream and downstream faces should be limited to 30 degrees shown in Figure 2. Dam crest thickness can be dictated as a constraint by the owner

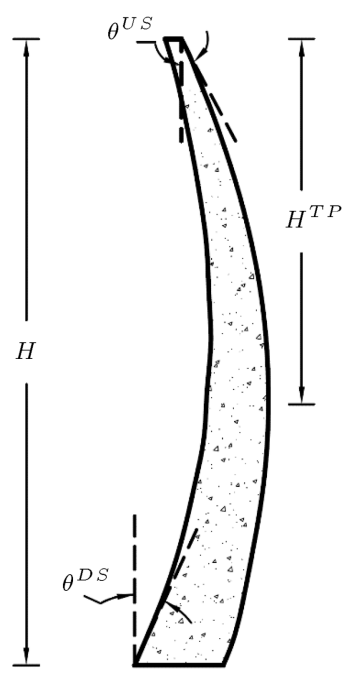

Figure 2. Maximum slope of overhang at the upstream and downstream faces.

Table 1. Design variables for an asymmetric arch dam.

\begin{tabular}{|c|c|c|c|c|c|c|c|}
\hline \multicolumn{7}{|c|}{ Horizontal arches variables } & \multirow{2}{*}{$\begin{array}{c}\text { Vertical arches of crown } \\
\text { cantilever variables } \\
Y_{i} \\
\end{array}$} \\
\hline & Thickne & & & $\mathbf{R a}$ & ius & & \\
\hline$t_{C 1}$ & $t_{A L 1}$ & $t_{A R 1}$ & $R_{U L 1}$ & $R_{U R 1}$ & $R_{D L 1}$ & $R_{D R 1}$ & $Y_{1}$ \\
\hline$t_{C 7}$ & $t_{A L 7}$ & $t_{A R 7}$ & $R_{U L 7}$ & $R_{U R 7}$ & $R_{D L 7}$ & $R_{D R 7}$ & $Y_{6}$ \\
\hline$t_{C 11}$ & $t_{A L 11}$ & $t_{A R 11}$ & $R_{U L 11}$ & $R_{U R 11}$ & $R_{D L 11}$ & $R_{D R 11}$ & $Y_{9}$ \\
\hline$t_{C 16}$ & $t_{A L 16}$ & $t_{A R 16}$ & $R_{U L 16}$ & $R_{U R 16}$ & $R_{D L 16}$ & $R_{D R 16}$ & $Y_{12}$ \\
\hline
\end{tabular}


or based on serviceability and possible traffic flow from the crest in the future. The constraint of limitation of the central angle of the arch at crest level, $\varphi$, is considered to be 110 degrees in this study. The central angle of the arch is the sum of the central angles of the arch on the left and right faces.

\subsection{Multi-objective particle swarm optimization}

2.4.1. Particle Swarm Optimization (PSO)

This algorithm categorized as meta-heuristic algorithms has been successfully used for continuous optimization problems and is used in this study [29]. The algorithm defines a set of particles and guesses them randomly. Then, an interactive process is carried out by changing the position of the particles and searching the space of design variables in order to improve the quality of the fitness function. Fitness function is estimated in an interactive way for particles to memorize the history of their best success which is called Pbest of that particle. Each particle is able to communicate with other particles to find the best observed position by the population called Gbest. Each $n$ dimensional particle in a population represents a response candidate $\boldsymbol{X}_{\boldsymbol{i}}=\left(\boldsymbol{x}_{\boldsymbol{i} \mathbf{1}}, \boldsymbol{x}_{\boldsymbol{i} \mathbf{2}}, \ldots, \boldsymbol{x}_{\boldsymbol{i n}}\right)$, for $i=$ $1,2, \ldots, n$ and is called population swarm $[30,31]$.

\subsubsection{Multi-objective Optimization in PSO (MOPSO)} MOPSO optimization algorithm was introduced in 2004 by Coello [32]. This algorithm is a generalization of PSO optimization algorithm used for solving multi-objective problems. In MOPSO algorithm, a concept which is called Archive or Repository is added to PSO algorithm and is known as hall of Fame. MOPSO algorithm allows storing Pareto solutions at each iteration using a repository of non-dominated solutions. Choosing the best global solution and the best personal recollection for each particle would be an important and fundamental step in the multi-objective optimization algorithm of swarm.

When the particles want to have a movement, a member of the archive is chosen as the leader. This leader must be a member of the archive and must be non-dominated. The members of archive represent Pareto front and include non-dominated particles. Instead of Gbest, a member of archive is selected. At PSO, there is no archive because there is only one objective and just one particle is the best. However, in MOPSO, there are some particles that are nondominated and are included among the solutions. The implementation process of this algorithm is as follows:

1. The required parameters are determined for the implementation of the MOPSO algorithm: Maximum iterations for the algorithm run, population size, the amount of positive constant coefficients to control exploration and exploitation in the search space, and the members of the repository;

2. The initial population is created;

3. The best personal memory of each particle is determined;

4. Non-dominant members of the population are isolated and stored in the archive;

5. Each particle selects a leader out of the archive and continues its movement (The speed gets updated);

6. The best personal memory of each of the particles gets updated;

7. New non-dominated members are added to the archive;

8. Dominated members of the archive are eliminated.

In case the conditions have not been met, the above process will be repeated from step number five.

The numbers of initial population and iterations are considered 30 and 180, respectively. The numbers of particles and iterations are considered according to Coello's recommendation. Number of iterations depends on the number of particles. A large volume of population causes less iterations, and also repository size is considered 24 for the optimization.

\section{Mathematical equation of arch dam shape}

The shape of an arch dam is of paramount importance in its ultimate behavior and eventually settles all the design criteria [33]. Arch dam shape can be distinguished by crown cantilever section shape as well as horizontal arches at different elevations. The geometrical parameters to define the shape of both crown cantilever and horizontal arched are brought in the following sections.

\subsection{Upstream crown cantilever shape}

The general equation of a conic function in Cartesian coordinate system can be written as:

$$
\left\{\begin{array}{l}
a x^{2}+b x y+c x^{2}+d x+e y+f=0 \\
\Delta=4 a c-b^{2} \\
\Delta<0 \quad \text { Hyperbola } \\
\Delta>0 \quad \text { Elipse } \\
\Delta=0 \quad \text { Parabola }
\end{array}\right.
$$

Crown cantilever can be defined using two elliptic conic functions of vertical coordinate for upstream and downstream faces as shown in Figure 3. In this study, to define crown cantilever shape, at first, upstream face of crown cantilever section was defined by an ellipse, and then crown cantilever thickness was approximated 


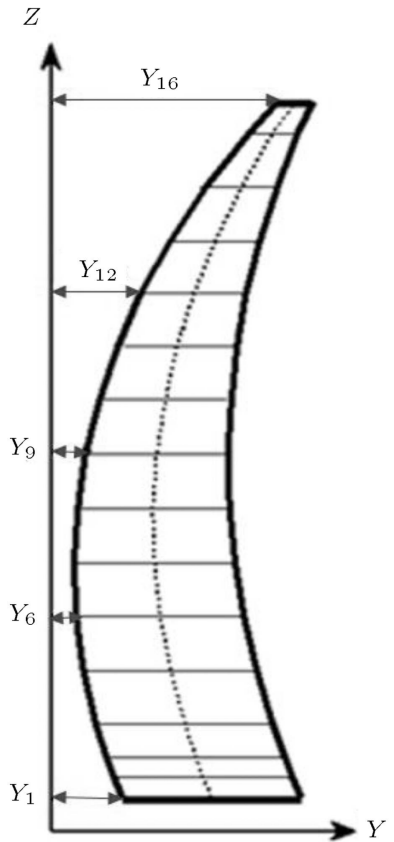

Figure 3. Crown cantilever upstream profile design variable.

by a third degree polynomial to complete the crown cantilever geometry.

In order to define an exact conic function based on Eq. (5), it is needed to determine 5 points on the upstream face of crown cantilever. $U$ would be the matrix of coordinates for these five points which can be written as follows:

$$
U=\left[\begin{array}{lllll}
Z_{0} & Z_{1} & Z_{2} & Z_{3} & Z_{4} \\
Y_{0} & Y_{1} & Y_{2} & Y_{3} & Y_{4}
\end{array}\right]
$$

where $Y_{i}$ is the distance of crown cantilever's upstream curve from dam axis, and $Z_{i}$ is dam height at point $i$, as shown in Figure 3.

Implementing coordinates of points on upstream face into Eq. (5) yields:

$$
M A=V,
$$

where:

$$
M=\left[\begin{array}{ccccc}
\left(Y_{0}\right)^{2} & Y_{0} Z_{0} & \left(Z_{0}\right)^{2} & Y_{0} & Z_{0} \\
\left(Y_{1}\right)^{2} & Y_{1} Z_{1} & \left(Z_{1}\right)^{2} & Y_{1} & Z_{1} \\
\left(Y_{2}\right)^{2} & Y_{2} Z_{2} & \left(Z_{2}\right)^{2} & Y_{2} & Z_{2} \\
\left(Y_{3}\right)^{2} & Y_{3} Z_{3} & \left(Z_{3}\right)^{2} & Y_{3} & Z_{3} \\
\left(Y_{4}\right)^{2} & Y_{4} Z_{4} & \left(Z_{4}\right)^{2} & Y_{4} & Z_{4}
\end{array}\right],
$$

$$
V=\left[\begin{array}{l}
1 \\
1 \\
1 \\
1 \\
1
\end{array}\right], \quad A=\left[\begin{array}{l}
a \\
b \\
c \\
d \\
e
\end{array}\right] .
$$

Knowing the coordinates of upstream face of these five points and assuming $f=-1$, the coefficients of upstream conic function can be obtained after inversing $M$ matrix and pre-multiplying it by $V$ as follows:

$$
M^{-1} \cdot V=\left[\begin{array}{l}
a \\
b \\
c \\
d \\
e
\end{array}\right]
$$

The conic function of the upstream face can be written as follows:

$$
F(Y, Z)=a Y^{2}+b Y Z+c Z^{2}+d Y+e Z+f=0 .
$$

Root of the conic function can be written as follows:

$$
U_{w}(Z)=\frac{-(b Z+d)+\sqrt{(b z+d)^{2}-4 a\left(c Z^{2}+e Z+f\right)}}{2 a} .
$$

To locate a tangent point location, it is required to obtain derivative of Eq. (11) which results in Eq. (12) as shown in Box I.

Substituting coefficients of conic functions from Eq. (9) into Eq. (12) and equating it with zero to obtain $Z$ gives tangent point location at height of crown cantilever in the upstream face from dam base. Substituting $Z$ in the equation of the upstream face will give $Y$ called Maximum Offset on Water Face, which would be the distance of tangent point from upstream axis in dam crest.

Maximum slopes of the tangent to the curve of the upstream face and the $Z$-axis at the crest and base of dam can be obtained as follows:

$$
\begin{aligned}
& \tan ^{-1}\left(D U_{w}\left(Z_{4}\right)\right)=\theta_{\text {Crest US }}, \\
& \tan ^{-1}\left(D U_{w}\left(Z_{0}\right)\right)=\theta_{\text {base US }}
\end{aligned}
$$

where $Z_{4}$ is dam crest level and $Z_{0}$ is dam base level.

The crown cantilever curve can be divided into

$$
D U_{w}(Z)=\frac{-b+[b(b Z+d)-2 a(2 c z+e)]\left[(b z+d)^{2}-4 a\left(c Z^{2}+e Z+f\right)\right]^{-0.5}}{2 a}
$$




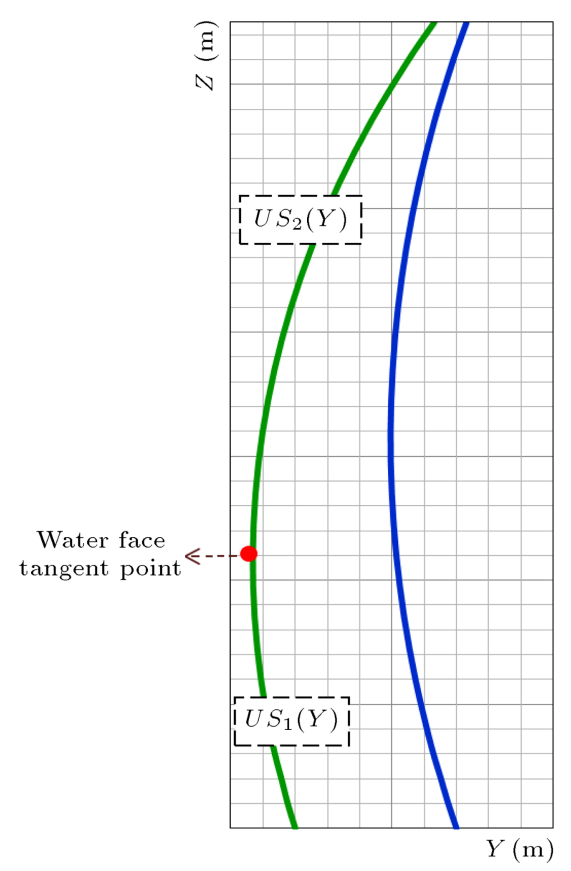

Figure 4. Cross section of crown cantilever for two-segment ellipse of upstream face.

two branches of the upper and lower parts of the tangent point, as shown in Figure 4:

$$
\begin{aligned}
& U S_{1}(Y)= \\
& \frac{-(b Y+e)+\sqrt{(b Y+e)^{2}-4 c\left(c Y^{2}+d Y+f\right)}}{2 c}, \\
& U S_{2}(Y)= \\
& \frac{-(b Y+e)-\sqrt{(b Y+e)^{2}-4 c\left(c Y^{2}+d Y+f\right)}}{2 c} .
\end{aligned}
$$

\subsection{Thickness of crown cantilever and horizontal arches}

In this study, changes in the thickness of the crown cantilever and left and right horizontal abutments are fitted with a third-degree polynomial of the vertical coordinate. Each polynomial was defined based on parameters of Table 1 for the corresponding parameters, as shown in Figure 5. Thus, thickness of crown cantilever and abutment thicknesses on the left and right can be written as follows $[1,3,8]$ :

$$
\begin{aligned}
& t_{c}(Z)=a_{0}+a_{1} Z+a_{2} Z^{2}+a_{3} Z^{3}, \\
& t_{A L}(Z)=b_{0}+b_{1} Z+b_{2} Z^{2}+b_{3} Z^{3}, \\
& t_{A R}(Z)=c_{0}+c_{1} Z+c_{2} Z^{2}+c_{3} Z^{3},
\end{aligned}
$$

where $t_{c}(Z), t_{A L}(Z)$, and $t_{A R}(Z)$ are crown, left, and right abutment thicknesses, respectively, and $Z$ is vertical coordinates with $a_{0}, \ldots, a_{3}, b_{0}, \ldots, b_{3}, c_{0}, \ldots, c_{3}$ as constant coefficients of the polynomials.

Knowing the thickness equation, downstream profile can be obtained as:

$$
Y(Z, \text { Downstream })=Y(Z, \text { Upstream })+t_{c}(Z) .
$$

\subsection{Radius of curvatures}

The third-degree polynomial is used to define the radii of curvature of water and air faces:

$$
\begin{aligned}
& \mathrm{R}_{\mathrm{UL}}(Z)=d_{0}+d_{1} Z+d_{2} Z^{2}+d_{3} Z^{3}, \\
& \mathrm{R}_{\mathrm{UR}}(Z)=e_{0}+e_{1} Z+e_{2} Z^{2}+e_{3} Z^{3}, \\
& \mathrm{R}_{\mathrm{DL}}(Z)=f_{0}+f_{1} Z+f_{2} Z^{2}+f_{3} Z^{3}, \\
& \mathrm{R}_{\mathrm{DR}}(Z)=g_{0}+g_{1} Z+g_{2} Z^{2}+g_{3} Z^{3},
\end{aligned}
$$

where $\mathrm{R}_{\mathrm{UL}}(Z), \mathrm{R}_{\mathrm{UR}}(Z), \mathrm{R}_{\mathrm{DL}}(Z), \mathrm{R}_{\mathrm{DR}}(Z)$ are the left and right radii of curvature of water and air faces. $Z$ is vertical coordinates; $d_{0}, \ldots, d_{3}, e_{0}, \ldots, e_{3}, f_{0}, \ldots, f_{3}$, $g_{0}, \ldots, g_{3}$ are the coefficients which can be found, as shown in Figure 5.

\subsection{Horizontal arches}

Parabolic conic functions are used to define horizontal arches of dam, as shown in Figure 6. The general equation of water and air face parabolas can be written as follows:

$$
Y=Y_{0}+\frac{\left(X-X_{0}\right)^{2}}{2 P} .
$$

The parabola is defined by the position of its apex $\left(Y_{0}\right)$ and its radius of curvature at the apex $(P)$. To define the horizontal section at an elevation, two parabolic curves are defined on the left and right sides as shown in Figure 7. Each side is divided into two segments: constant thickness and variable thickness segments. The thickness of the dam in a horizontal section is constant in the first segment and increases by parabolic function in the second section. Coefficients $K_{r}$ and $K_{l}$ determine portion of the length of arch with constant thickness in the right and left banks. In this paper, $K_{r}$ and $K_{l}$ are equal $2 / 3$.

In Table $2, x_{e d L}$ and $x_{e d R}$ are lengths of segment with constant thickness in left and right banks, respectively (Figure 7).

Total number of horizontal layers from base to the crest of the dam is equal to 16 used for the purpose of generating elements in vertical direction.

\section{Finite-element model}

A finite-element code developed based on design variables vector is able to generate finite-element model 


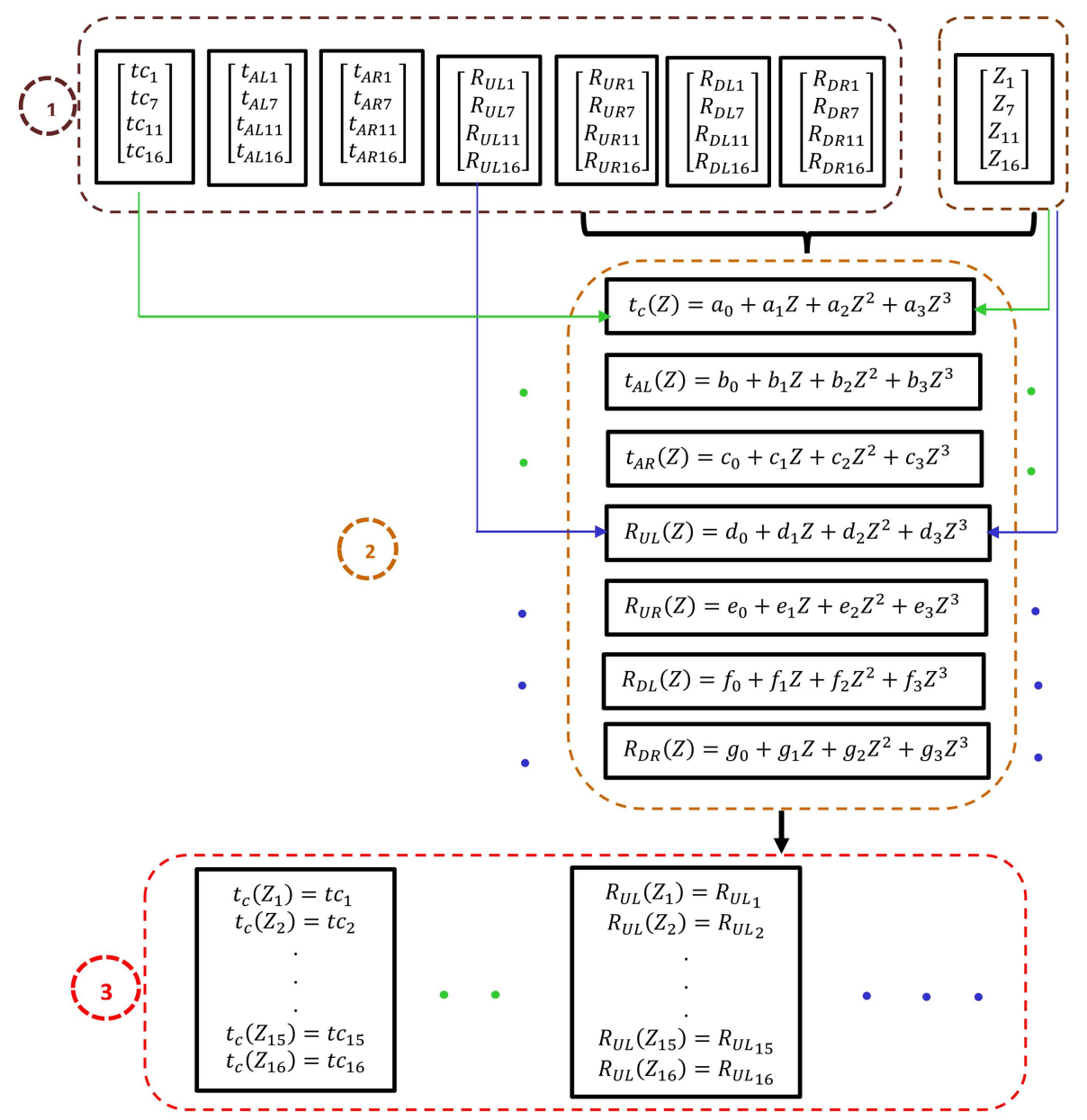

1. Input variables according to Table 1 in specified elevations that produced from each iteration of optimization algorithm.

2. Fitness function.

3. Generated thicknesses and radiuses in all elevations ( 16 levels) for using in related equations These parameters and others are utilized for generation of node coordinates in the finite element model of the dam body

Figure 5. The flowchart of generation of crown cantilever thicknesses.

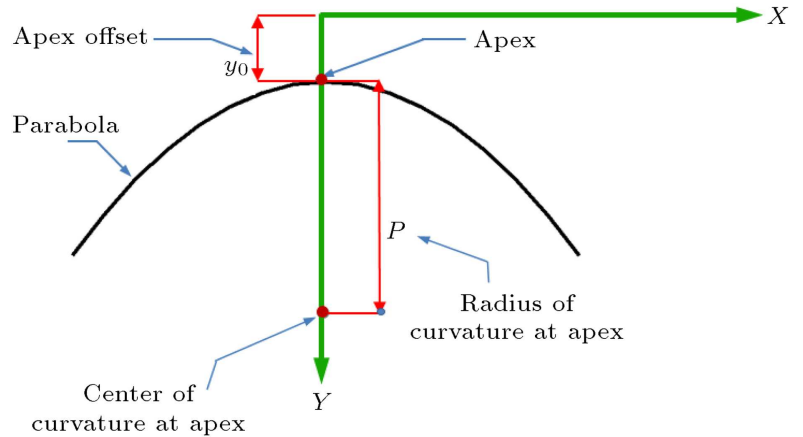

Figure 6. Parabola definition.

of dam automatically. Finite-element mesh of damfoundation system generated by the code is shown in Figure 8. Height and span of finite-element model of dam body are 325 and 451 meters, respectively.

Dam was discretized in thickness by two layers

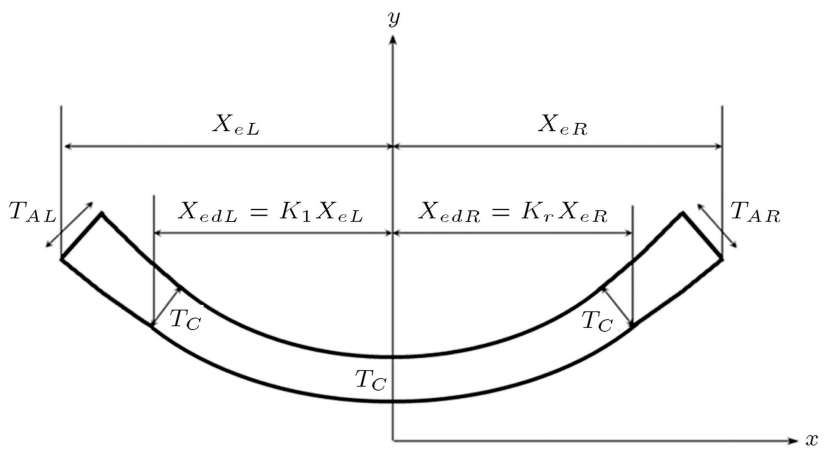

Figure 7. Horizontal arch of the dam body at elevation [8].

of 20-node brick elements. Foundation is assumed as massless with outer surfaces of the foundation parallel to the global axis. Nodal displacement constraints are applied to the nodes located on the lateral surfaces and 
Table 2. Constant thickness and variable thickness segments equations in right and left halves of horizontal arch.

\begin{tabular}{ccc}
\hline Right half & $T_{a R}(x)=T_{C}+\frac{\left(x-x_{e d R}\right)^{2}\left(T_{A R}-T_{C}\right)^{2}}{\left(x_{e R}-x_{e d R}\right)^{2}}$ & $x_{e d R}<x<x_{e R}$ \\
& $T_{a R}=T_{C}$ & $x<x_{e d R}$ \\
& & \\
Left half & $T_{a L}(x)=T_{C}+\frac{\left(x-x_{e d L}\right)^{2}\left(T_{A L}-T_{C}\right)^{2}}{\left(x_{e L}-x_{e d L}\right)^{2}}$ & $x_{e d L}<x<x_{e L}$ \\
& $T_{a L}=T_{C}$ & $x<x_{e d L}$ \\
\hline
\end{tabular}
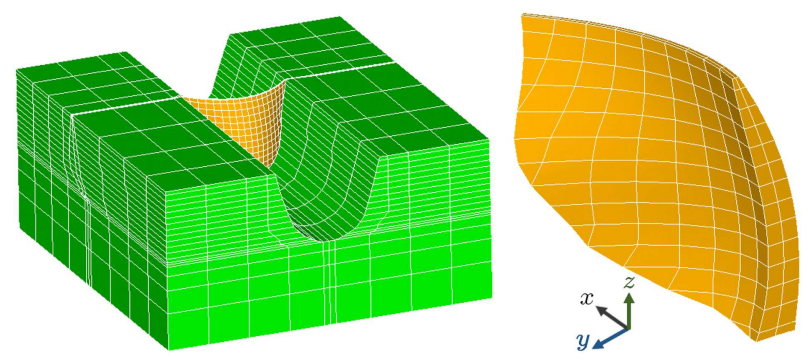

Figure 8. Finite-element mesh of dam-foundation system.

the lower surfaces of foundation. The dimensions of the foundation in stream and cross-stream directions are considered 2 and 3 times wider than the width of the valley and its depth is considered 2 times taller than the height of the dam body.

The modulus of elasticity of mass concrete was taken as $24 \mathrm{GPa}$ and that of the foundation rock was taken as $10 \mathrm{GPa}$. Poisson's ratio of mass concrete and rock is taken as 0.18 and 0.25 , respectively. Mass density of the concrete is chosen as $2400 \mathrm{~kg} / \mathrm{m}^{3}$ and no gravity load is applied to the foundation rock.

\section{Stage construction}

Stage construction is important in the static analysis of the design purposes, and it is necessary to be considered in the shape optimization of concrete arch dam [1]. In the absence of stage construction modeling, when all dead loads are applied at once, stress distribution under dead load would be incorrect causing fictitious stresses $[3,7,18,34,35]$.

Large concrete dams are made up of several blocks called monoliths. Monoliths are separated by vertical contraction joints, which would be connected to each other after grouting with low tensile strength during dam construction. In finite-element modeling for stage construction, 8 stages of concrete placing were considered by utilizing even and odd blocks simulation. Monoliths with even numbers are analyzed separately first, and then the odd monoliths are analyzed.

\section{MOPSO analysis}

MOPSO optimization algorithm was used for the analysis of arch dam. In this study, the optimization procedure was carried out simultaneously using two

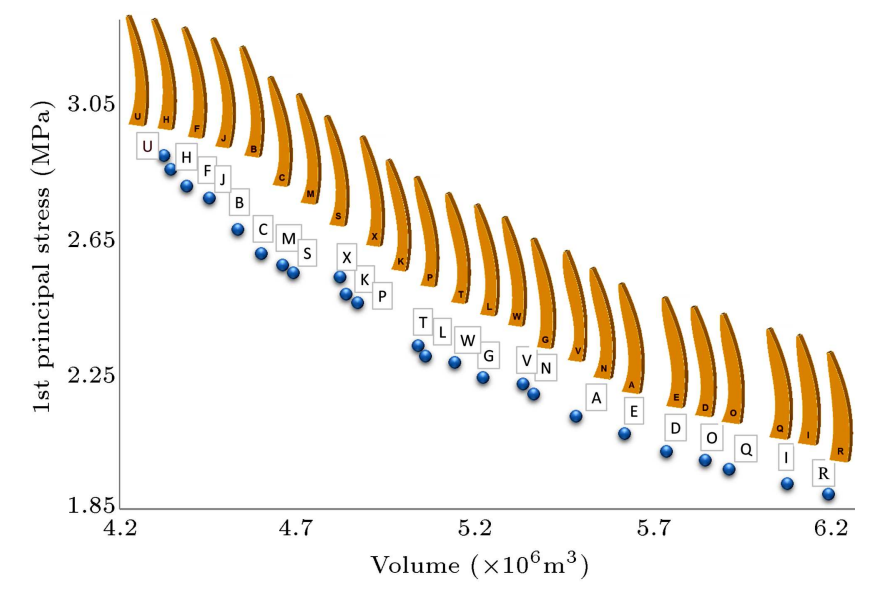

Figure 9. Pareto front alternatives and shape of the crown cantilever optimal designs.

objectives of minimizing concrete volume of dam body and limiting maximum principal stress. Since these two goals are competing with each other, there is a set of near-optimal solutions to different values of volumes and tensile stresses. A trade-off exists between two objectives requiring an approach for justification to obtain the best couple. Results of MOPSO analysis are shown in Figure 9. Results of the two-objective optimization based on Pareto chart are shown in Figure 9 where cost of placing concrete (economic criteria) versus tensile stress (safety criteria) is demonstrated. Total of 24 different cases were obtained from MOPSO analysis. None of the 24 obtained optimal cases (A-X) takes precedence over the others, which is a general property of the Pareto front. In many cases, the decision-maker would prefer to establish a balance in choosing between the objective functions. Figure 9 shows that from economical point of view, case $\mathrm{U}$ is the best choice, while from safety point of view, case $\mathrm{R}$ is the best choice out of Pareto front.

\section{Decision making}

The purpose of MOPSO analysis is to obtain nondominated solutions or Pareto archive. Decisionmakers ought to choose the best solution after achieving the Pareto set. Results of Pareto set are the optimal solutions of arch dam as shown in Figure 9. The most optimum case depends on the importance of economic 
and safety goals for a decision-maker. This can change from one decision-maker to another.

In this study, two different methods are given for helping decision-makers in their decision making. These methods for the case of an arch dams are Lombardi coefficient and equilibrium point methods.

\subsection{Lombardi coefficient}

Lombardi coefficient can be used for the optimal designs of Pareto front for the purpose of evaluation. Lombardi, a Swiss expert designer in 1986, introduced a coefficient called Lombardi, which is a measure of safe design [36-38]. The results of Lombardi coefficient, as given in Eq. (19), are shown in Figure 10:

$$
C=\frac{F^{2}}{V \cdot H}
$$

In the above equation, $F$ is the surface area of the mid-body of the dam, $V$ is the volume of the dam body, and $H$ is the height of the dam. Lombardi has recommended for dams, with height around $300 \mathrm{~m}$, to have a Lombardi coefficient of 10 or lower.

It can be seen in Figure 10 that an increase in Lombardy coefficient causes higher value of tension stresses in dam body. Based on the results of Lombardy coefficient for all the cases, one can decide that case $\mathrm{E}$ is the most optimal case.

\subsection{Equilibrium point method}

Equilibrium point method is used to help decisionmakers in their choices from Pareto set. This hypothetical point focuses on improving both optimality criteria simultaneously. In this method, utopia point is defined as minimum objective functions with practically unfeasible and unattainable objectives. The closest distance to the utopia point on the Pareto front is chosen as the optimal solution, as shown in Figure 11. Utopia point coordinates in cases of Pareto set are (4.32 and 1.9). In order to find the closest distance to the utopia point in two-dimensional space, the second norm is used which

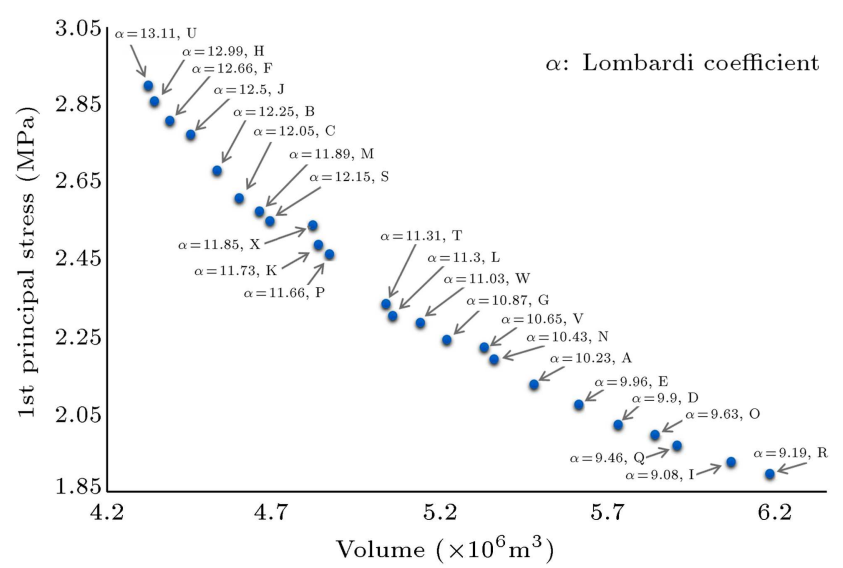

Figure 10. Results of Lombardi coefficients in Pareto set.

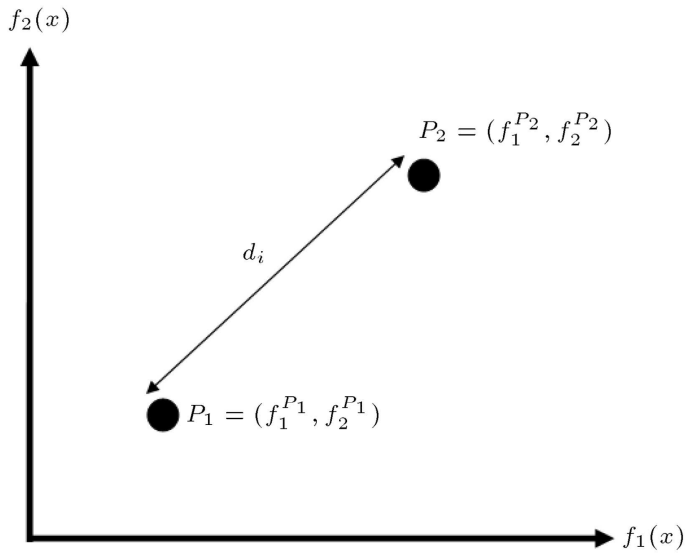

Figure 11. Definition of Euclidean norm.

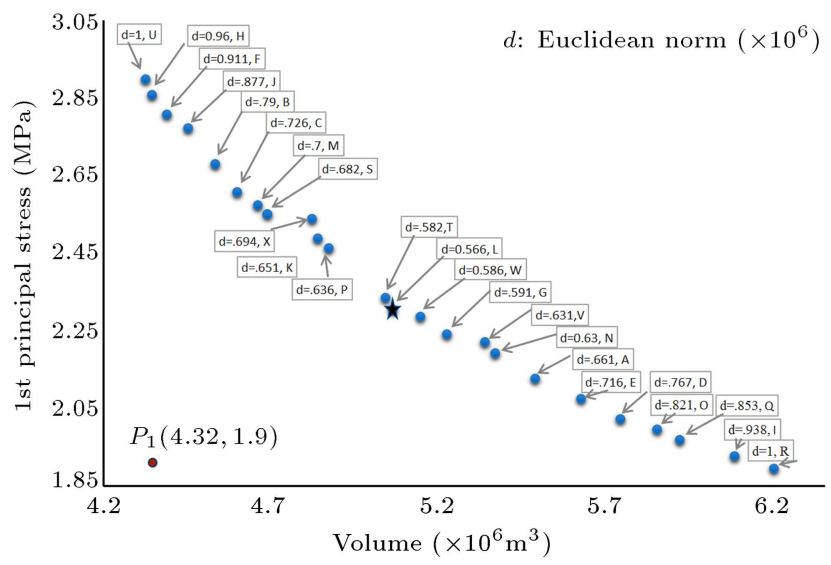

Figure 12. Results of Euclidean norm in Pareto set.

is the Euclidean distance $d_{i}$, as presented in Figure 11 and Eq. (20):

$$
\left\|P_{2}-P_{1}\right\|=\sqrt{\sum_{i=1}^{2} \omega_{i}\left(\frac{\left(f i^{P 2}-f i^{P 1}\right)}{\left(f_{i}^{\max }-f_{i}^{\min }\right)}\right)^{2}},
$$

where $\omega_{i}$ refers to the weights of criteria $\left(\omega_{i}=1\right)$, and $f_{i}^{\max }$, and $f_{i}^{\min }$ are the maximal and minimal value of $f_{i}(x)$. In the figure, $P_{1}$ is the utopia point and $P_{2}$ is a case in Pareto set. Results of Euclidean distance are shown in Figure 12. The closest optimal design of the Pareto front to utopia point is case $\mathrm{L}$.

\section{Conclusions}

MOPSO optimization algorithm was introduced for solving shape optimization of concrete arch dams. Results of the two-objective optimization based on Pareto front were compared where cost of placing concrete (economic criteria) versus tensile stress (safety criteria) was used as objectives. To help decision-makers in their decision, two different methods are proposed.

These methods for the case of an arch dams are Lombardi coefficient and equilibrium point methods. 
The obtained results indicate that these two methods can be helpful for designers without experience and information of the previous design.

\section{References}

1. Takalloozadeh, M. and Ghaemian, M. "Shape optimization of concrete arch dams considering abutment stability", Scientia Iranica, 21(4), pp. 1297-1308 (2014).

2. Bofang, Z., Rao, B., Jia, J. and Li, Y. "Shape optimization of arch dams for static and dynamic loads", J. Struct. Eng., ASCE, 118(11), pp. 2996-3015 (1992).

3. Pourbakhshian, S. and Ghaemain, M. "Shape optimization of arch dams using sensitivity analysis", KSCE Journal of Civil Engineering, 20(15), pp. 19661976 (2016). DOI: $10.1007 / \mathrm{s} 12205-015-0135-4$.

4. Akbari, J., Ahmadi, M.T. and Moharrami, H. "Advances in concrete arch dams shape optimization", Applied Mathematical Modelling, 35, pp. 3316-3333 (2011). DOI:10.1016/j.apm.2011.01.020.

5. Bofang, Z., Bin, R., Jin Sheng, J. and Yisheng, L. "Shape optimization of arch dams for static and dynamic loads", Journal of Structural Engineering, 118(11) pp. 2996-3015 (1992).

6. Bofang, Z. "Optimum design of arch dams", Dam Eng. I, 2, pp. 131-145 (1990).

7. Pourbakhshian, S. and Ghaemain, M. "Investigating stage construction in high concrete arch dams", Indian Journal of Science and Technology, 8(14), pp. 1-4 (2015). DOI: $10.17485 / \mathrm{ijst} / 2015 / \mathrm{v} 8 \mathrm{i} 14 / 69510$.

8. Pourbakhshian, S., Ghaemain, M. and Jogatae, A. "The shape optimization of concrete arch dams considering stage construction", Scientia Iranica, 23(1), pp. 21-35 (2016).

9. Seyedpoor, S.M., Salajegheh, J., Salajegheh, E. and Gholizadeh, S. "Optimum shape design of arch dams for earthquake loading using a fuzzy inference system and wavelet neural networks", Engineering Optimization, 41(5), pp. 4073-493 (2009). DOI: $10.1080 / 03052150802596076$.

10. Yin, D., Wei, Y. and Huibo, L. "Shape optimization for arch dam with sequential quadratic programming method", Applied Mechanics and Materials, 580-583, pp. 1961-1965 (2014). DOI:10.4028/ www.scientific.net/AMM.580-583.1961.

11. Stoyang, G., Stefan, G.T., Anton, D.T.T., and Russel, M.G. "A numerical procedure for arch dam shape optimisation for static and seismic loads", 6th International Conference on Dam Engineering, Lisbon, Portugal, February 15-17, pp. 597-610 (2011).

12. Yishen, L. and Bofang, Z. "The optimum design of arch dams and curve of arch thickness", Journal of Hydraulic Engineering, 11, pp. 26-33 (1985).
13. Xiao-fei, Z., Shou-yi, L. and Yao-Long, C. "Optimization of geometric shape of Xiamen arch dam", Advances in Engineering Software, 40, pp. 105-109 (2009). DOI:10.1016/j.advengsoft.2008.03.013.

14. Wassermann, K. "Three-dimensional shape optimization of arch dams with prescribed shape functions", $J$. Struct. Mech., 11(4), pp. 465-489 (1983-84).

15. Tse-Min Yao and Kyung K. Choi "Shape optimal design of arch dam", Journal of Structural Engineering, 115(9), pp. 2401-2405 (1989).

16. Ulker, M. and Savas, S. "Shape optimization of arch dams under dynamic load", Imo Teknik Dergi, 263, pp. 3973-3986 (2006) (In Turkish).

17. Kirillov, Y.V. "Optimization of the form of a concrete arch dam", Power Technology and Engineering, 24(5), pp. 338-348 (1990).

18. Hariri-Ardebili, M.A. and Mirzabozorg, H. "Feasibility study of Dez arch dam heightening based on nonlinear numerical analysis of existing dam", Archives of Civil Engineering, Lix, 1, pp. 21-49 (2013). DOI: 10.2478/ace-2013-0002.

19. Sun, L.S. and Du, F. "Robust optimization for shape design of arch dams based on strain energy", Applied Mechanics and Materials, 777, pp. 94-100 (2015).

20. Wen-jun, S., Linsong, S., Dexin, W. and Chunguang, L. "Bin-objective shape optimization of arch dams", Journal of Hohai University, 28(3), pp. 39-43 (2000). (in Chinese).

21. Lin-Song, S., Wei-hua, Z. and Neng-gang, X. "Multiobjective optimization for shape design of arch dams based on game theory", Journal of Hohai University (Natural Sciences), 34(4), pp. 392-396 (2006) (in Chinese).

22. Hai, J., Gao, L. and Ming-sheng, Y. "Bin-objective shape optimization based on linear programming model of arch dam", Journal of Harbin Institute of Technology, 14(3), pp. 436-439 (2007).

23. Nenggang, X., Linsong, S., Jiahan, B. and Hao, F. "Multi-objective optimization design of arch dam shape based on unfish cooperation game model", Shuili Xuebao, 38(9), pp. 1109-1114 (2007) (in Chinese).

24. Nenggang, X., Yuwan, C., Linsong, S. and Lu, W. "Multi-objective Bionics design methods based on mixed-behavior game", Chinese Journal of Theoretical and Applied Mechanics, 40(2), pp. 229-236 (2008).

25. Sun, L., Zhang, W. and Xie, N. "Multi-objective optimization for shape design of arch dams", Computational Methods in Engineering and Science, EPMESC $X$, pp. 1009-1017, China (2006).

26. Nadir, W., Kim, I.Y. and de Weck, O.L. "Structural shape optimization considering both performance and manufacturing cost", 10th AIAA/ISSMO Multidisciplinary Analysis and Optimization Conference, Albany, New York, pp. 1-12 (1 September 2004).

27. Raphael, J.M. "Tensile strength of concrete", in ACI Journal Proceedings, pp. 158-165, ACI (March-April 1984). 
28. Engineers, U.S.A. C.o., Arch Dam Design, EM 11102-2201, Washington, DC (1994).

29. El-Ghazali, Talbi, Metaheuristics: From Design to Implementation, John Wiley and sons, 8(4) (2009).

30. Sayyaadi, H., Babaie, M. and Farmani, M.R. "Implementing of the multi-objective particle swarm optimizer and fuzzy decision-maker in exergetic, exergoeconomic and environmental optimization of a benchmark cogeneration system", Energy, 36(8), pp. 4777-4789 (2011). DOI: 10.1016/j.energy.2011.05.012.

31. Zadeh, P.M., Roshanian, J. and Farmani, M.R. "Particle swarm optimization for multiobjective collaborative multidisciplinary design optimization", 51st AIAA/ASME/ASCE/AHS/ASC Structures, Structural Dynamics, and Materials Conference, pp. 1-11 (2010).

32. Coello, C.A.C., Pulido, G.T. and Lechuga, M.S. "Handling multiple objectives with particle swarm optimization", IEEE Transactions on Evolutionary Computation, 8(3), pp. 256-279 (2004).

33. Coello, C.A.C. and Lechuga, M.S. "MOPSO: A proposal for multiple objective particle swarm optimization", IEEE, pp. 1051-1056 (2002).

34. Yi, L., Guoxin, Z., Bofang, Z. and Feng, S. "Actual working performance assessment of super-high arch dams", Journal of Performance of Constructed Facilities, ASCE, 30(20), pp. (040150011-1)-(040150011-15) (2015). DOI: 10.1061/(ASCE) CF.1943-5509.0000745, 04015011.

35. Engineering Guidelines for the evaluation of hydropower projects, Chapter 11 - Arch Dams, Federal Energy Regulatory Commission Division of Dam Safety and Inspections, Washington, DC 20426 (1999).
36. Fanelli, M. and Lombardi, G. "On the Lombardi slenderness coefficient for assessing the cracking potential of arch dams", Proceeding of the International Symposium on Arch Dams, Nanjing (China), pp. 1-4 (October 17-20, 1992).

37. Lombardi, G. "Kolnbrein dam: A special solution for a special problem", Water Power- ICOLD Issue Vienna, pp. 1-16 (April 1991).

38. Su, H., Wu, Z., Gu, Y., Hu, J. and Wen, Z. "Game model of safety monitoring for arch dam deformation", Science in China Series E: Technological Sciences, $\mathbf{5 1}$ (Supp. II), pp. 76-81 (2008).

\section{Biographies}

Majid Pouraminian is a $\mathrm{PhD}$ candidate in the Structural Engineering Department of Civil Engineering, Science and Research Branch, Islamic Azad University, Tehran, Iran. His research interests are mathematical methods in multi-objective optimization, and size and shape optimization of structures, and post-Pareto analysis. In recent years, she has been working on shape optimization of arch dam and open spandrel arch bridges.

Mohsen Ghaemian is a Professor in Civil Engineering Department of Sharif University of Technology, Tehran, Iran. His current research activities Include dynamic responses of gravity and arch dams, dam reservoir interaction effects, seismic response of dams due to non-uniform excitations, shape optimization of arch dams, and nonlinear behavior of concrete dams. 